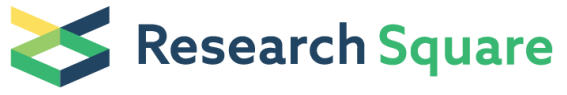 \\ Preprints are preliminary reports that have not undergone peer review. \\ They should not be considered conclusive, used to inform clinical practice, or referenced by the media as validated information.
}

\section{Limitations in Cataract Surgical Services in Children in Ethiopia: A Nationwide Survey of Pediatric Cataract Surgeons}

\author{
Mulusew Asferaw ( $\nabla$ muasf@yahoo.com ) \\ WGGA Eye Center,Pediatric Ophthalmology and strabismus unit, Addis Ababa, \\ Kumale Tolesa \\ Jimma University Hospital, Department of Ophthalmology, Jimma \\ Sadik Taju Sherief \\ Menelik II Hospital, Addis Ababa University, Department of Ophthalmology, Addis Ababa \\ Bezawit Tadegagne \\ St. Paul's Hospital Millennium Medical College, Department of Ophthalmology, Addis Ababa \\ Mandefro Sintayehu \\ Bisidimo Hospital, Haramaya University, Department of Ophthalmology, Harer \\ Addisu Worku \\ Menelik II Hospital, Addis Ababa University, Department of Ophthalmology, Addis Ababa \\ Teshager Wondale \\ Gondar University Hospital, University of Gondar, Department of Ophthalmology, Gondar \\ Emebet Girma \\ Hawassa Referral Hospital, Hawassa University, Department of Ophthalmology, Hawassa \\ Zelalem Gizachew \\ Menelik II Hospital, Addis Ababa University, Department of Ophthalmology, Addis Ababa \\ Clare Gilbert \\ International Centre for Eye Health, Department of Clinical Research, London School of Hygiene \& Tropical Medicine, London \\ Geoffrey Woodruff \\ Leicester Royal Infirmary, Department of Ophthalmology, Leicester
}

\section{Research Article}

Keywords: Pediatric cataract surgery, child eye health tertiary facility, pediatric ophthalmologists, Ethiopia

Posted Date: February 22nd, 2021

DOI: https://doi.org/10.21203/rs.3.rs-184256/v1

License: (c) (i) This work is licensed under a Creative Commons Attribution 4.0 International License. Read Full License

Version of Record: A version of this preprint was published at BMC Ophthalmology on December 1st, 2021. See the published version at https://doi.org/10.1186/s12886-021-02190-0. 


\section{Abstract}

Background: Bilateral cataract is a significant cause of blindness in Ethiopia. This study aimed to identify the resources available for cataract surgery in children, and to assess current surgical practices, surgical output and factors affecting the outcome of surgery in Ethiopia.

Methods: A Google Forms mobile phone questionnaire was emailed to nine ophthalmologists known to perform cataract surgery in young children.

Results: All nine responded. All but one had received either 12- or 3-5-month's training in pediatric ophthalmology with hands-on surgical training. The other surgeon had received informal training from an experienced colleague and visiting ophthalmologists. Five worked in the capital, Addis Ababa, and they worked in six public referral hospitals and one private center.

Over 12 months (2017-2018) 508 children underwent surgery; 84 (17\%) children had bilateral and 424 (83\%) had unilateral cataract, mainly following trauma (mean 66 (range 18-145 standard deviation (SD) \pm 47 ) eyes/surgeon). There were substantially fewer surgeons per million population (nine for 115 million population) than recommended by the World Health Organization and they were unevenly distributed across the country.

Methylcellulose and rigid intraocular lenses were generally available but less than $50 \%$ of facilities had a sharp vitrectomy cutter and cohesive viscoelastic. Mean travel time outside Addis Ababa to a facility offering pediatric cataract surgery was 10 hours.

Conclusion: Despite the high number of cases per surgeon, the output for bilateral cataracts was far lower than required. More wellequipped ophthalmologists trained in pediatric cataract surgery are urgently required, with deployment to under-served areas.

\section{Background}

The prevalence of blindness in children aged 0-15 years is higher in the sub-Saharan African (SSA) Global Burden of Diseases superregion $(0.71 / 1000$ children) than in other regions, due to greater exposure to risk factors and lower access to public health interventions and eye care services [1]. In 2020, SSA was the region with the highest number of blind and severely visually impaired and blind children $(350,000$, excluding refractive error), with approximately 300 affected children per 10 million population [1]. The proportion of blindness in SSA which is avoidable with today's knowledge is also high, as many of the conditions are amenable to primary preventive measures, such as measles immunization and vitamin A supplementation, and tertiary prevention, such as surgery for congenital and developmental cataract. However, corneal blindness from measles and vitamin A deficiency is declining, largely as a result of public health interventions, and in many countries cataract is now the principal cause of avoidable blindness, estimated to account for $17 \%$ of blindness in SSA in 2020[1]. Similar findings have been reported from Ethiopia, where bilateral cataract was responsible for $33 \%$ of severe visual impairment and blindness in a key informant study[2], and 10\% in two studies of children attending special education[3, 4].

To address blinding eye diseases in children in low and middle income countries, in 2002 the World Health Organization (WHO) recommended that one tertiary eye care facility for children be established for every 10 million population [5]. Recommendations were also made for minimal staffing requirements, including an ophthalmologist trained in pediatric ophthalmology, and the minimal essential equipment, which included an operating microscope with co-axial illumination and a vitrectomy machine for cataract surgery. Ethiopia currently has a population of 115 million, which indicates that there should be 11 or 12 of these facilities across the country.

In high income countries good visual acuity outcomes following bilateral cataract surgery can be achieved, with at least $50 \%$ having an acuity of $6 / 18$ or better after surgery.[6,7] Good results have also been described from resource poor settings, with more than $80 \%$ of children in a study from Nepal having a corrected visual acuity of 6/12 or better.[8] However, outcomes in Africa, where children typically present very late for surgery, vary widely. In two Tanzanian studies, $54 \%$ and $62 \%$ of children achieved an acuity of $6 / 18$ in the better eye $[9,10]$ but only $30 \%$ of children in Zambia and $25 \%$ in South Africa achieved this level of acuity $[11,12]$. There are only two studies of the outcome of surgery in Ethiopia. In a recent retrospective study in Gondar, $58 \%$ of eyes in children with bilateral cataract achieved $6 / 18$ or better, or fix and follow [13]. In an earlier study in Southern Ethiopia, only $11 \%$ of children achieved an acuity of $6 / 18$ or better [14].

In view of the ongoing problem of cataract blindness in children and the variable outcomes in Ethiopia, we initiated the CHICOE project (Children's Improvement in Cataract Outcome in Ethiopia). This first publication is authored by all nine ophthalmologists undertaking cataract surgery in young children (age 0-5 years) in Ethiopia, and provides a national picture of cataract surgery in children in terms of the training the ophthalmologists had received, the resources available, the volume of surgery and surgical techniques, and ophthalmologists' views on the main reasons for poor outcomes and delay in surgery. 


\section{Methods}

In August 2018, the corresponding author emailed a two-part mobile phone survey questionnaire in Google Forms to all nine surgeons known to undertake cataract surgery in young children in Ethiopia. Part I consisted of 17 questions about the institution where the surgeon operates and their training in pediatric ophthalmology. Part II was a 20-question survey of surgical practices, including the number of eyes operated by each surgeon over the previous 12 months, the youngest age at which they implant an intraocular lens, and the availability of equipment and consumables. Surgeons were also invited to comment on factors they judged to have limited the outcome of their surgery over the previous year and the relative importance of different causes of delay in surgery. To compare the findings in the two government hospitals in Addis Ababa with the four centers outside the capital, the surgeons' assessment of each factor was scored 1-4.

A third questionnaire consisting of 14 supplementary questions was developed based on the responses to the first two questionnaires. Each surgeon was asked if they were aware of any other surgeons or institutions in Ethiopia undertaking cataract surgery in children. They were asked what proportion of children age 0-18 years with cataract were operated by themselves, other participants in this study, or by other ophthalmologists.

\section{Results}

All nine surgeons believed to undertake cataract surgery in young children responded to the questionnaire, and none were aware of any others.

\section{Centers undertaking cataract surgery in young children}

The surgeons were based in seven facilities: five government university teaching hospitals, one government non-teaching hospital and one private facility. Five worked in two government hospitals and a private facility in the capital city, Addis Ababa. Among the nine regional states and two city administrations in Ethiopia, only three states and one city have a center which undertakes cataract surgery in young children (Figure 1). For parents of children with cataract who live outside Addis, the mean travel time to another facility offering cataract surgery was 10.2 hours.

\section{Surgical output}

The total number of children operated for cataract between September 2017 and August 2018 was 508 which included 84 children with bilateral cataract. At four institutions a further 71 older children were operated on by other surgeons, including 12 operations by visiting pediatric ophthalmologists from high income countries (Table 1).

\section{Availability of equipment and consumables}

There was no clear association between the availability of consumables and equipment and location i.e., in or outside Addis Ababa.

The availability of a sharp vitrectomy cutter was as follows: for $>80 \%$ of cases in the private centre in the capital and in one of the peripheral centres; for $50-80 \%$ of cases in the remaining peripheral hospitals; and in the capital for $1-49 \%$ of cases in one centre, and never available in the other centre (Figure 2A).

Surgeons in all three facilities in Addis and in two peripheral facilities always had access to a microscope with X-Y shift capable of providing a bright red reflex. However, a surgeon in a government hospital in Addis reported seeing a red reflex in only $50-80 \%$ of cases, and another surgeon in a peripheral facility reported that the microscope was only available for $50-80 \%$ of bilateral cases (Figure 2B). A peripheral centre had a microscope that consistently provided a bright red reflex but lacked X-Y shift.

In all facilities methylcellulose was available for $>80 \%$ of bilateral cases operated over the previous year (Figure $2 \mathrm{~A}$ ). The availability of hyaluronic cohesive viscoelastic was as follows: never available in three facilities ( 2 in the capital, 1 in peripheral); available for $1-49 \%$ of cases in three facilities ( 2 in peripheral, 1 in the capital); and for $50-80 \%$ in one peripheral center.

Rigid intraocular lenses (IOL) were available for $>80 \%$ of surgeries in six of the seven facilities and foldable IOLs were available for $>80 \%$ of cases in only 2 centers. The availability of other equipment and consumables varied with handheld keratometry, Trypan blue and aphakic glasses, never available in at least one facility (Figure 2A).

Training and surgical techniques 
Six of the nine surgeons had completed a one-year pediatric ophthalmology fellowship, but the opportunities for hands on surgery during this training varied (Table 2). Two surgeons were enrolled in a fellowship training program at the time of the survey but had not yet completed this. Another surgeon had not had formal fellowship training but was being trained and mentored by one of the other participating surgeons and visiting ophthalmologists from high income countries.

The mean number of eyes operated for pediatric cataract by each surgeon throughout their career was 384 (range 27-950). The youngest average age at which surgeons had implanted an IOL was 14 months (range 4-24 \pm 8.0 ). The mean age beyond which surgeons judged primary posterior capsulotomy not to be required was 7.4 (range $5-10 \pm 1.9$ ) years (Table 2).

There was a wide range in techniques for anterior capsulotomy in children aged 0-5 years: one surgeon used a can opener technique in all cases, one used vitreorhexis in all cases and one used high frequency diathermy in $15 \%$ of cases (Figure $3 \mathrm{~A}$ ). Four surgeons never or almost never used manual curvilinear continuous capsular rhexis (CCCR) even in older children (Figure 3B). These four surgeons included one who had completed training more than four years earlier, and two who had completed a one-year fellowship but with only three or five months hands-on surgical training.

\section{Factors affecting outcome of surgery for bilateral cataract over the 12 months}

Eight of the nine surgeons stated that inadequate equipment or consumables had been a significant or major problem limiting the outcome in most or many children (Figure 4A and B). Five reported post-operative optical correction as a major problem in most cases and two volunteered that a major limiting factor was the lack of regular access to paediatric anaesthesia.

All nine surgeons judged that delay in surgery was the most important factor which limited the outcome of surgery for children with bilateral cataract. They reported that delays occurred at every step, from delayed recognition of a problem by parents, delay in seeking advice, inappropriate initial advice and other parental commitments.

\section{Discussion}

This study has shown that useful information can be gained by a Google Forms survey of surgeons in a resource poor environment.

We identified nine paediatric cataract surgeons working in seven facilities providing paediatric cataract surgery, three in the capital city Addis Ababa, and four outside the capital. These centres serve a total population of 115 million i.e., one for every 16.4 million people, which is lower than the WHO recommendation of one Child Eye Health Tertiary Facility (CEHTF) with well trained staff and adequate resources for every 10 million population by the year 2020. The services are also very poorly distributed. The two government facilities in the capital city serve a population of approximately 8 million as well as some patients from outside the capital region who travel to Addis for surgery. In contrast, the four government centres outside Addis, each with one surgeon, nominally serve the rest of the population (an average of one per 26.8 million people). The northern part of the country is particularly under-served. Addressing this maldistribution of resources will be challenging. However, the essential packages for eye care being developed by WHO as an integral component of Universal Health Coverage will include congenital cataract, which may improve human resource planning for eye care in children [15]. This development provides an opportunity for advocacy with the Ministries of Health in Ethiopia for more resources for child eye care services. Additional services outside the capital city would reduce travel and costs for parents, and promote earlier access, which is important as surgeons in this study reported delay in presentation to be the major cause of poor outcomes.

All but one of the surgeons had undergone formal training in pediatric cataract surgery and the total number of cataract operations performed by each surgeon indicates extensive surgical experience. Recently there has been substantial support of fellowship training in pediatric ophthalmology in Ethiopia by two international non-government organizations, Orbis International and the Himalayan Cataract Project, with at least one established pediatric cataract surgeon now contributing to the training of a newly appointed surgeon. This reflects what was reported in a baseline and follow up study of tertiary level child eye care facilities in SSA, which demonstrated that staffing and infrastructure had improved significantly between the two studies $[16,17]$.

The method used for anterior capsulotomy gives an indication of the sophistication of the techniques surgeons were exposed to during training. In this study four surgeons never or almost never used CCCR even in older children and two performed can-opener capsulotomy in almost all cases. This is likely explained by the fact that most of the surgeons had been taught anterior capsulotomy using a vitrector rather than CCCR. In addition, because small incision cataract surgery is used for adults in Ethiopia which does not require CCCR, unlike phacoemulsification, they would not have gained skills in CCCR by operating on adults. The lack of capsulorrhexis forceps suitable for use through a small corneal incision may also have contributed to the relatively infrequent use of CCCR. There is a clear a need for further

Page $4 / 13$ 
training with provision of relevant equipment, which all the surgeons would welcome. The recently proposed pediatric ophthalmology academic partnership between Canada and Ethiopia could help to address these gaps [18].

Compared to national studies from high income countries, the number of cases operated per surgeon in our study was very high. For example, in a survey of US paediatric cataract surgeons in $2003,86 \%$ operated on less than 21 eyes a year [19] compared with only one surgeon in our study where the mean number of eyes operated was 66 . This reflects the low number of pediatric ophthalmologists, with only one for every 12.8 million population. The volume of cataract surgery by the private facility in Addis was very small although this surgeon contributes to teaching and providing services in two government facilities. The cataract surgical output is not adequate for the need, as unoperated cataract is a significant cause of blindness in children in Ethiopia [2, 4].

Our surgeons reported that two thirds of the children they operated on had unilateral cataract, mostly following trauma, which is a higher than in studies in high income countries (25-30\%) [7]. Other studies in Africa have also shown that serious ocular injury in children is very common, and is often caused by playing with sticks [20]. Preventive measures, such as health education in schools, or 'toy for stick' exchange programs could reduce this morbidity.

Surgeons often cited "other parental commitments" as contributing to delayed surgery, which is likely to be exacerbated by uneven distribution of services and the long travel distances required to access them. This is consistent with other studies of inequalities in access to health care [21] and suggests that many children with visually significant cataract in Ethiopia never present for surgery.

Our study has limitations as it was questionnaire based rather than observational and relied on data collected retrospectively and recall of surgeons' experiences. Moreover, in a rapidly changing situation, this survey provides only a snapshot for the year 2017/2018. However, in the absence of other information about pediatric cataract surgical practice in Ethiopia, our study provides the first information on the limitations of these services.

\section{Conclusions}

The number of CEHTFs is lower than the WHO recommendation, and the services that are available are poorly distributed across the country. It is, therefore, not surprising that late presentation is an important cause of poor outcomes. Many centers lack the equipment and consumables considered essential for high quality cataract surgery in young children.

There is a need to increase the number and distribution of pediatric ophthalmologists and ensure they are adequately trained and equipped to provide high quality surgery. A minimum of five more CEHTFs with the full complement of competent allied eye health professionals are required to meet WHO recommendations. Advocacy with the Ministry of Health to address these challenges is very important, working in partnership with NGOs.

We propose that this survey is followed by a retrospective review of the visual acuity outcome of bilateral cataract surgery in Ethiopia to provide baseline data, followed by a prospective national study following the provision of additional resources.

\section{Abbreviations}

CCCR: curvilinear continuous capsular rhexis; CEHTF: Child eye health tertiary facility; CHICOE: Children's Improvement in Cataract Outcome in Ethiopia; IOL: Intraocular lens; NGO: Non-governmental organization; PPC= Primary posterior capsulotomy; SD: standard deviation; SSA: Sub-Saharan Africa; WHO: World Health Organization

\section{Declarations}

\section{Acknowledgement}

Not Applicable

\section{Ethics approval and consent to participate}

The need for ethics approval was waived by Ethics Review Committee of WGGA Eye Center. Informed consent was obtained from all participants of the study.

\section{Consent for publication}


Not applicable

\section{Availability of data and materials}

The datasets generated during and analyzed during the current study are not publicly available due to presence of personal identification of participants, but are available from the corresponding author on reasonable request.

\section{Competing interests}

The authors declare that they have no competing interests.

\section{Funding}

There was no funding source for this study.

\section{Authors' contributions}

Study concept and design: M.A, G.W, C.G, and K.T; Analysis and interpretation of data: M.A, G.W, and C.G; Drafting of the manuscript: G.W, M.A, C.G, K.T; Critical revision of manuscript for important intellectual content: G.W, M.A, C.G, K.T, E.G, S.T.S, B.T, M.S, T.W, A.W, and Z.G. All authors gave final approval of the article.

\section{Authors' information}

${ }^{1}$ WGGA Eye Center, Pediatric Ophthalmology and Strabismus Unit, Addis Ababa, Ethiopia

2Jimma University Hospital, Department of Ophthalmology, Jimma, Ethiopia

${ }^{3}$ Menelik II Hospital, Addis Ababa University, Department of Ophthalmology, Addis Ababa, Ethiopia

${ }^{4}$ St Paul's Hospital Millenium Medical College, Department of Ophthalmology, Addis Ababa, Ethiopia

${ }^{5}$ Bisidimo Hospital, Haramaya University, Department of Ophthalmology, Harer, Ethiopia

${ }^{6}$ Gondar University Hospital, University of Gondar, Department of Ophthalmology, Gondar, Ethiopia

${ }^{7}$ Hawassa Referral Hospital, Hawassa University, Department of Ophthalmology, Hawassa, Ethiopia

${ }^{8}$ International Centre for Eye Health, Department of Clinical Research, London School of Hygiene \& Tropical Medicine, London, UK

${ }^{9}$ Leicester Royal Infirmary, Department of Ophthalmology, Leicester, UK

\section{References}

1. Rahi JS and Gilbert CE. Chapter 2: Epidemiology and the impact of visual impairment in children worldwide. In Taylor and Hoyt's Pediatric Ophthalmology and Strabismus. 2021 6th Ed. Scott Lambert and Christopher Lyons. Saunders, Elsevier Ltd, London. In press

2. Demissie BS, Solomon AW. Magnitude and causes of childhood blindness and severe visual impairment in Sekoru District, Southwest Ethiopia: a survey using the key informant method. Trans R Soc Trop Med Hyg 2011;105:507-11.

3. Kello AB, Gilbert C. Causes of severe visual impairment and blindness in children in schools for the blind in Ethiopia. Br J Ophthalmol 2003;87:526-30.

4. Asferaw M, Woodruff G, Gilbert C. Causes of severe visual impairment and blindness in students in schools for the blind in Northwest Ethiopia. BMJ Glob Health 2017;2:e000264.

5. World Health Organization. A five-year project for the prevention of childhood blindness. WHO/PBL02.88. Geneva.

6. Chak M, Wade A, Rahi JS on behalf of the British Congenital Cataract Interest Group. Long-Term Visual Acuity and Its Predictors after Surgery for Congenital Cataract: Findings of the British Congenital Cataract Study. Invest Ophthalmol Vis Sci 2006;47:4262-9.

7. Ambroz SC, Töteberg-Harms M, Hanson JVM, et al. Outcome of Pediatric Cataract Surgeries in a Tertiary Center in Switzerland. J Ophthalmol 2018;2018:3230489. 
8. Adhikari S, Shrestha UD. Pediatric cataract surgery with hydrophilic acrylic intraocular lens implantation in Nepalese children. Clin Ophthalmol. 2018;12:7-11.

9. Bowman RJ, Kabiru J, Negretti G, et al. Outcomes of bilateral cataract surgery in Tanzanian children. Ophthalmol 2007;114:2287-92.

10. Mndeme FG, Mmbaga BT, Msina M, et al. Presentation, surgery and 1-year outcomes of childhood cataract surgery in Tanzania. $\mathrm{Br} J$ Ophthalmol 2020;00:1-7

11. Mboni C, Gogate PM, Phiri A, et al. Outcomes of pediatric cataract surgery in the copperbelt province of Zambia. J Pediatr Ophthalmol Strab 2016;53:311-

12. Gogate P, Parbhoo D, Ramson P, et al. Surgery for sight: outcomes of congenital and developmental cataracts operated in Durban, South Africa. Eye 2016;30:406-

13. Asferaw M, Mekonen S, Woodruff G, et al. Outcome of paediatric cataract surgery in Northwest Ethiopia: a retrospective case series. Br J Ophthalmol 2019;103:112-

14. Tomkins $\mathrm{O}$, Ben-Zion I, Moore DB, et al. Outcomes of pediatric cataract surgery at a tertiary care center in rural southern Ethiopia. Arch Ophthalmol 2011;129:1293-7.

15. Keel S, Jennifer R Evans JR, Block S, et al. Strengthening the integration of eye care into the health system: methodology for the development of the WHO package of eye care interventions. BMJ Open Ophthalmology 2020;5:e000533.

16. Kishiki E, van Dijk K and Courtright P. Strategies to improve follow-up of children after surgery for cataract: findings from Child Eye Health Tertiary Facilities in sub-Saharan Africa and South Asia. Eye 2016;30:1234-41.

17. Agarwal PK, Bowman R, Courtright P. Child eye health tertiary facilities in Africa. J AAPOS 2010;14:263-6.

18. . Kletke SN, SobokaJG, Dimaras H, et al. Development of a pediatric ophthalmology academic partnership between Canada and Ethiopia: a situational analysis. BMC Medical Education 2020; 20:438-47.

19. Wilson ME, Bartholomew LR, Trivedi RH. Pediatric cataract surgery and intraocular lens implantation. Practice styles and preferences of the 2001 ASCRS and AAPOS memberships. J Cataract Refract Surg 2003; 29:1811-20.

20. Abraham D, Vitale S, West S, et al. Epidemiology of Eye injuries in rural Tanzania. J Ophthalm Epidemiol 2009;2:85-94.

21. Weiss DJ, Nelson A, Gibson HS, et al. A global map of travel time to cities to assess inequalities in accessibility in 2015. NatureMedicine 2018; 553 333-6.

22. https://commons.wikimedia.org/wiki/File:Ethiopia_Population_density_1km_source_AfriPop_10v4.pdf.

\section{Tables}

Table 1 Pediatric cataract surgical centers in Ethiopia 


\begin{tabular}{|c|c|c|c|c|c|c|}
\hline $\begin{array}{l}\text { Name of } \\
\text { center }\end{array}$ & $\begin{array}{l}\text { Location } \\
\text { (City/Region) }\end{array}$ & $\begin{array}{l}\text { Type of } \\
\text { hospital }\end{array}$ & $\begin{array}{l}\text { Children aged } 0- \\
18 \text { years having } \\
\text { cataract surgery in } \\
\text { previous } 12 \\
\text { months }\end{array}$ & $\begin{array}{l}\text { Number of } \\
\text { children } \\
\text { operated by } \\
\text { non- } \\
\text { participating } \\
\text { surgeons }\end{array}$ & $\begin{array}{l}\text { Number of } \\
\text { participating surgeons } \\
\text { undertaking cataract } \\
\text { surgery on children } 0 \text { - } \\
5 \text { years }\end{array}$ & $\begin{array}{l}\text { Travel time to } \\
\text { nearest institution } \\
\text { offering pediatric } \\
\text { cataract surgery } \\
\text { (hours) }\end{array}$ \\
\hline $\begin{array}{l}\text { Menelik II } \\
\text { Hospital }\end{array}$ & Addis Ababa & $\begin{array}{l}\text { Government } \\
\text { University } \\
\text { Hospital }\end{array}$ & 159 & 42 & 3 & 1 \\
\hline $\begin{array}{l}\text { St Paul's } \\
\text { Millennium } \\
\text { Medical } \\
\text { College } \\
\text { Hospital }\end{array}$ & Addis Ababa & $\begin{array}{l}\text { Government } \\
\text { University } \\
\text { Hospital }\end{array}$ & 40 & 0 & $2^{*}$ & 1 \\
\hline $\begin{array}{l}\text { WGGA Eye } \\
\text { Centre }\end{array}$ & Addis Ababa & $\begin{array}{l}\text { Private } \\
\text { Centre }\end{array}$ & 6 & 0 & $1^{*}$ & 1 \\
\hline $\begin{array}{l}\text { Bisidimo } \\
\text { Hospital }\end{array}$ & $\begin{array}{l}\text { Bisidimo, } \\
\text { Oromia }\end{array}$ & $\begin{array}{l}\text { Government } \\
\text { Hospital } \\
\text { (non- } \\
\text { teaching) }\end{array}$ & 25 & 10 & 1 & 12 \\
\hline $\begin{array}{l}\text { Gondar } \\
\text { University } \\
\text { Hospital }\end{array}$ & $\begin{array}{l}\text { Gondar, } \\
\text { Amhara }\end{array}$ & $\begin{array}{l}\text { Government } \\
\text { University } \\
\text { Hospital }\end{array}$ & 142 & 17 & $2^{\star}$ & 14 \\
\hline $\begin{array}{l}\text { Jimma } \\
\text { University } \\
\text { Hospital }\end{array}$ & $\begin{array}{l}\text { Jimma, } \\
\text { Oromia }\end{array}$ & $\begin{array}{l}\text { Government } \\
\text { University } \\
\text { Hospital }\end{array}$ & 127 & 2 & 1 & 10 \\
\hline $\begin{array}{l}\text { Hawassa } \\
\text { Referral } \\
\text { Hospital }\end{array}$ & $\begin{array}{l}\text { Hawassa, } \\
\text { SNNPR }\end{array}$ & $\begin{array}{l}\text { Government } \\
\text { University } \\
\text { hospital }\end{array}$ & 80 & 0 & 1 & 5 \\
\hline
\end{tabular}

*One study surgeon operated at two other centers in addition to their base center.

SNNPR = Southern Nations, Nationalities, and Peoples' Region

Table 2 Training and experience of nine Ethiopian participating pediatric cataract surgeons 


\begin{tabular}{|c|c|c|c|c|c|c|c|c|c|c|}
\hline \multirow{3}{*}{$\begin{array}{l}\text { Surgeon } \\
\text { / year } \\
\text { qualified }\end{array}$} & \multicolumn{4}{|c|}{$\begin{array}{l}\text { Duration (months) and location of } \\
\text { training in pediatric ophthalmology }\end{array}$} & \multicolumn{4}{|c|}{ Pediatric cataract surgeries } & \multicolumn{2}{|c|}{ Surgical techniques } \\
\hline & \multirow{2}{*}{$\begin{array}{l}\text { Fellowship } \\
\text { or post } \\
\text { residency } \\
\text { training }\end{array}$} & \multirow{2}{*}{$\begin{array}{l}\text { Hands- } \\
\text { on } \\
\text { surgical } \\
\text { training }\end{array}$} & \multirow[t]{2}{*}{$\begin{array}{l}\text { Country } \\
\text { where } \\
\text { trained }\end{array}$} & \multirow{2}{*}{$\begin{array}{l}\text { Months } \\
\text { since } \\
\text { completion } \\
\text { of training }\end{array}$} & \multirow[t]{2}{*}{$\begin{array}{l}\text { Under } \\
\text { supervision }\end{array}$} & \multirow{2}{*}{$\begin{array}{l}\begin{array}{l}\text { Total } \\
\text { career }\end{array} \\
\text { Eyes }\end{array}$} & \multicolumn{2}{|c|}{$\begin{array}{l}\text { Operations in } \\
\text { previous } 12 \\
\text { months }\end{array}$} & \multirow{2}{*}{$\begin{array}{l}\text { Youngest } \\
\text { age at IOL } \\
\text { implantation } \\
\text { (years) }\end{array}$} & \multirow{2}{*}{$\begin{array}{l}\text { Age } \\
\text { after } \\
\text { which } \\
\text { PPC not } \\
\text { required } \\
\text { (years) }\end{array}$} \\
\hline & & & & & & & Eyes & $\begin{array}{l}\text { Children } \\
\text { with } \\
\text { bilateral } \\
\text { cataract }\end{array}$ & & \\
\hline A, 2011 & 8 & 5 & Nepal & $\begin{array}{l}\text { Not } \\
\text { complete }\end{array}$ & 10 & 100 & 18 & 3 & 2 & 8 \\
\hline B, 2016 & 12 & 11 & Tanzania & 7.5 & 40 & 290 & 137 & 18 & 1.2 & 8 \\
\hline C, 2010 & 12 & 12 & Tanzania & 52.4 & 200 & 701 & 100 & 20 & 1.5 & 10 \\
\hline D, 2018 & 5 & 3 & $\begin{array}{l}\text { South } \\
\text { Korea and } \\
\text { Nepal }\end{array}$ & $\begin{array}{l}\text { Not } \\
\text { complete }\end{array}$ & 37 & 192 & 145 & 20 & 0.3 & 10 \\
\hline E, 2011 & 12 & 5 & $\begin{array}{l}\text { USA and } \\
\text { Nepal }\end{array}$ & 7.5 & 40 & 120 & 32 & 2 & 2 & 5 \\
\hline$F, 2011$ & 13 & 13 & Canada & 24.5 & 30 & 330 & 27 & 1 & 1 & 5 \\
\hline G, 2010 & 12 & 5 & $\begin{array}{l}\text { Nepal, } \\
\text { Israel and } \\
\text { USA }\end{array}$ & 7.3 & 600 & 750 & 74 & 13 & 0.6 & 5 \\
\hline H, 2011 & 3 & 3 & $\begin{array}{l}\text { Mentoring } \\
\text { at place } \\
\text { of work }\end{array}$ & $\begin{array}{l}\text { Not } \\
\text { Complete }\end{array}$ & 10 & 27 & 24 & 2 & 2 & 8 \\
\hline I, 2010 & 12 & 12 & $\begin{array}{l}\text { Tanzania } \\
\text { and Nepal }\end{array}$ & 46.5 & 150 & 950 & 35 & 5 & 0.3 & 8 \\
\hline
\end{tabular}

$\mathrm{IOL}=$ Intraocular lens; PPC= Primary posterior capsulotomy

\section{Figures}




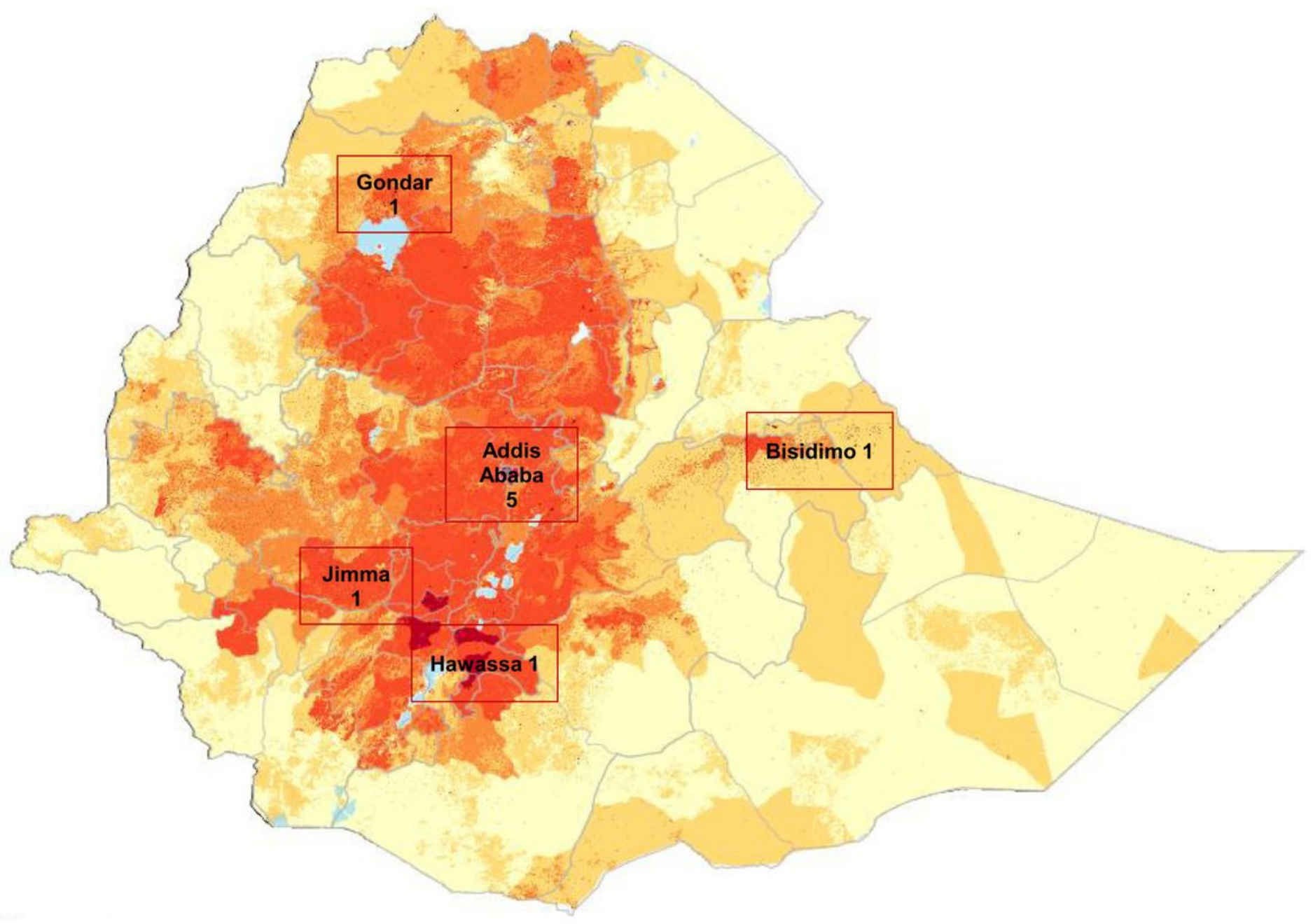

Figure 1

Map of population density of Ethiopia showing the location of the seven facilities where the study ophthalmologists work [22]. [ Adapted from @Amibreton/https://commons.wikimedia.org/wiki/File:Ethiopia_Population density 1 km source_Af riPop_10v4.pdf/Creative Commons Attribution-Share Alike 3.0 Unported ] Note: The designations employed and the presentation of the material on this map do not imply the expression of any opinion whatsoever on the part of Research Square concerning the legal status of any country, territory, city or area or of its authorities, or concerning the delimitation of its frontiers or boundaries. This map has been provided by the authors. 

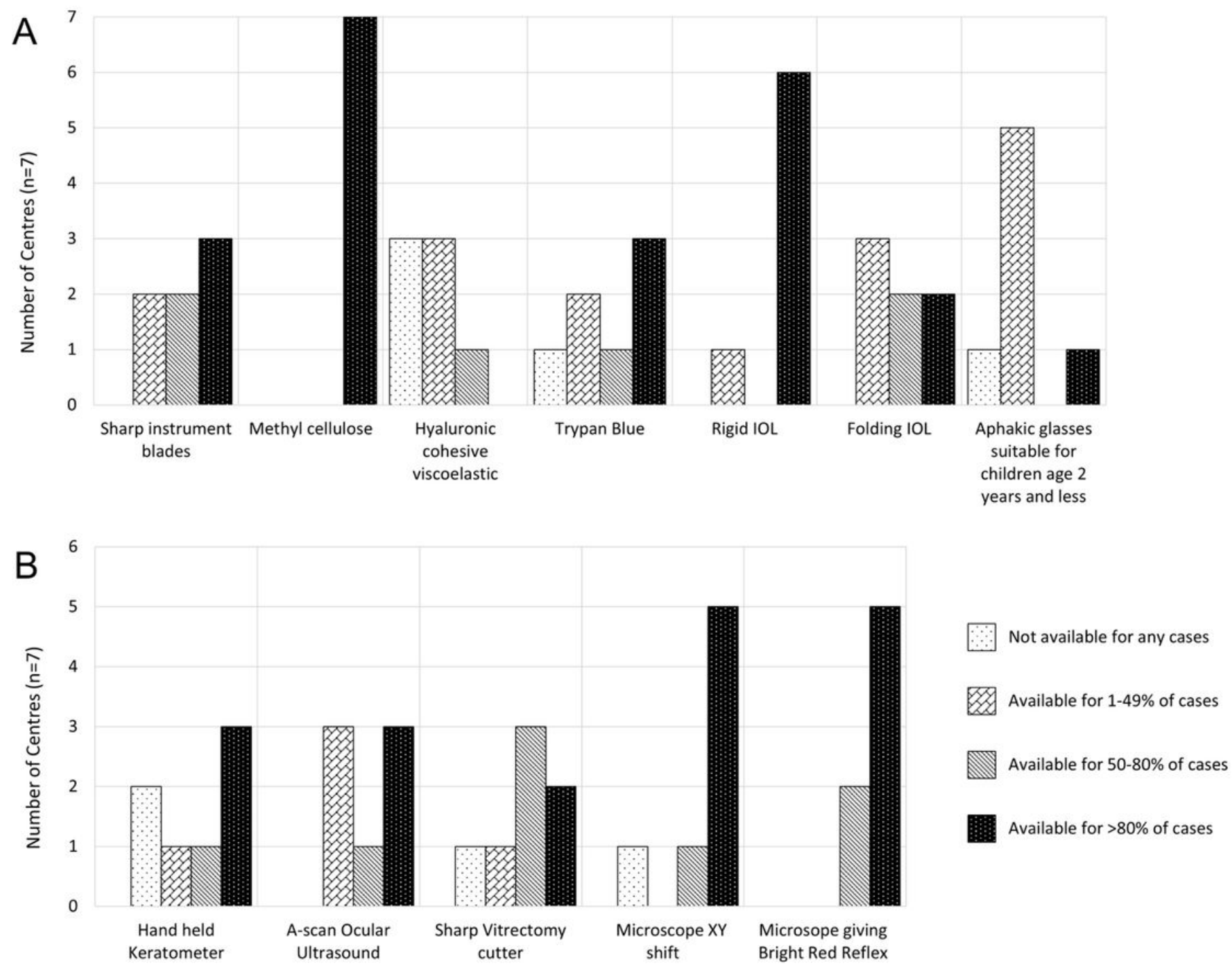

Figure 2

A. consumables and B. equipment for cataract surgery in children in seven study facilities 

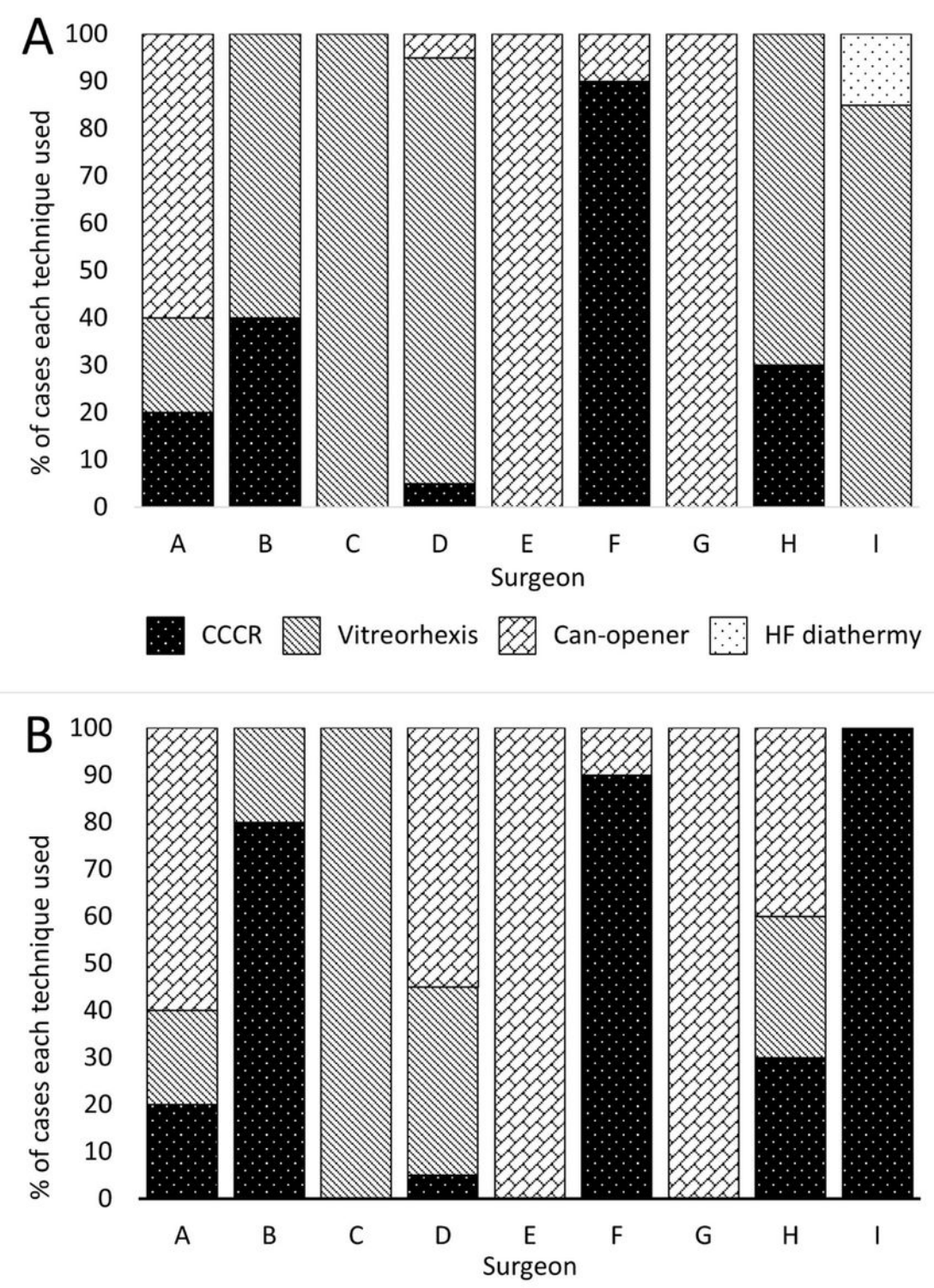

\section{Figure 3}

Techniques used for managing the anterior capsule A. in children aged 0-5 years B. in children older than 5 years 


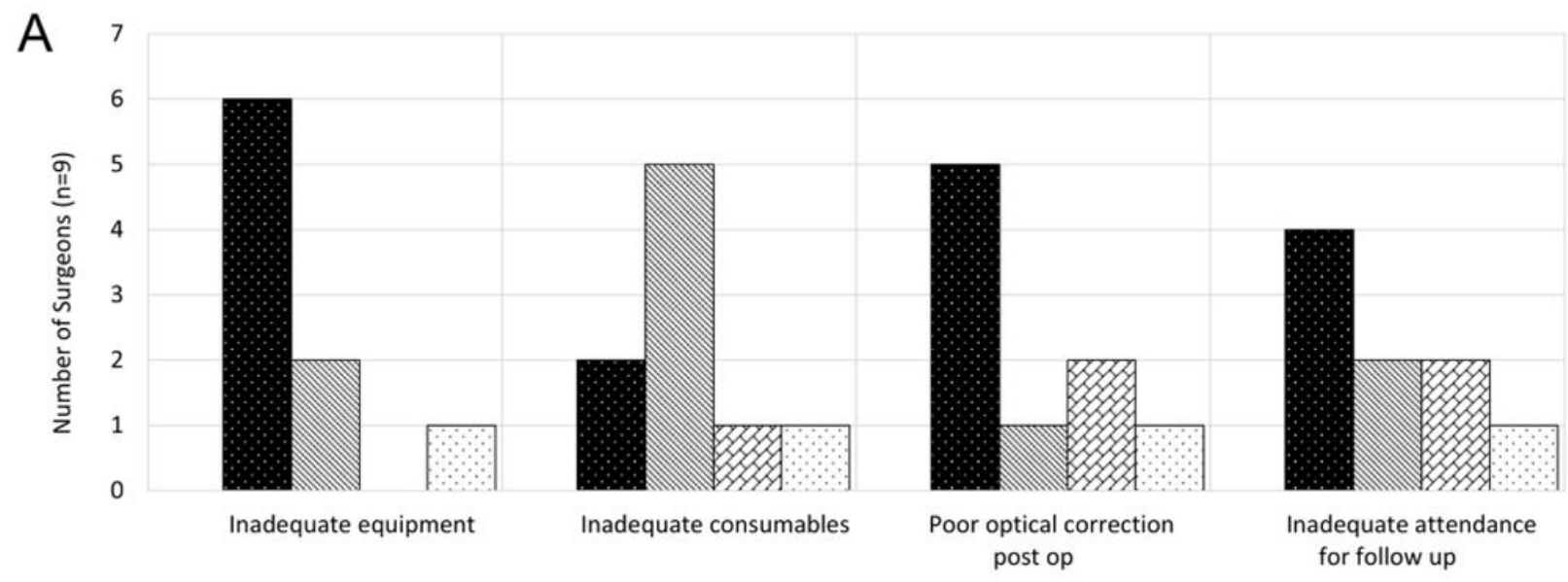

Major problem affecting most patients

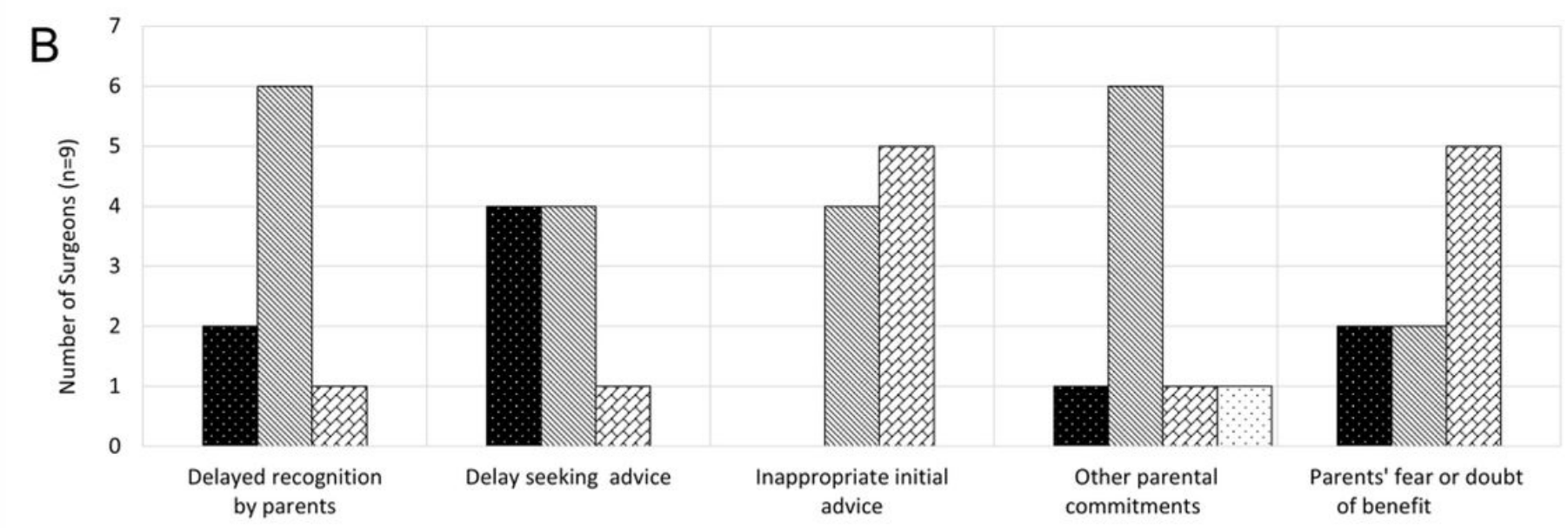

\section{Figure 4}

Factors affecting the outcome of surgery A. lack of equipment B. reason for delayed surgery 